\title{
Profesionalni stres kod medicinskih sestara i tehničara
}

1 Samka Ekić

1 Ana Primorac

1 Boris Vučić

1 Klinička bolnica Dubrava, Zagreb, Hrvatska

\section{Sažetak}

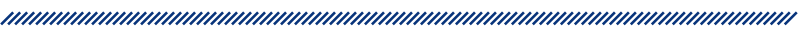

Cilj istraživanja bio je provjeriti utjecaj stresa na izvršavanje svakodnevnih radnih aktivnosti medicinskih sestara i tehničara.

Istraživanje se provodilo anonimno, primjenom upitnika konstruiranog isključivo za ovu svrhu. Upitnikom su obuhvaćeni sociodemografski podaci ispitanika, stresori prisutni kod svih radnika unutar profesije, specifični stresori koji se javljaju na rukovodećim mjestima te zdravstveni problemi ispitanika. U statističkoj obradi kontinuirane varijable prikazane su aritmetičkom sredinom i standardnom devijacijom. $U$ istraživanju su sudjelovala 363 ispitanika koji rade na različitim radnim mjestima, odnosno na odjelu, u poliklinici te $u$ dijagnostici. Većina ispitanika radi na odjelu u smjenama, njih 175 (50,7\%). Od ukupnog broja ispitanika koji rade na odjelu $86(24,9 \%)$ ih radi na odjelu intenzivne skrbi bolesnika.

U sklopu cilja istraživanja bilo je potrebno utvrditi kako su pojedini stresori unutar navedene profesije rangirani po intenzitetu. Na temelju dobivenih rezultata može se zaključiti da dominiraju stresori koji su povezani s osjećajem neadekvatne naknade i opsegom nepredvidivosti posla - kao što su 24-satna odgovornost te donošenje hitnih odluka bez mogućnosti konzultacije. Prekapacitiranost poslom i nedostatak vremena za bavljenje bolesnikom kod sestara na rukovodećem mjestu ocijenjeni su kao najintenzivniji stresor, a izoliranost od kolegica i kolega s obzirom na funkciju na rukovodećem mjestu kao najmanje intenzivan stresor. Stresori međusobne komunikacije unutar tima nisko su ocijenjeni.

Kao što je spomenuto, istraživanjem su s pomoću upitnika obuhvaćene i zdravstvene tegobe koje su nastale kao posljedice stresa. Od ukupnog broja ispitanika njih $212(60,90 \%)$ navodi postojanje zdravstvenih problema kroničnog karaktera, pri čemu zdravstveni problemi traju dulje od jedne godine. Dobiveni rezultati ukazuju i na učestalost kardiovaskularnih bolesti (povišeni krvni tlak, cirkulacijske smetnje), probavnih smetnji i lokomotornih smetnji.

Ključne riječi: Stres, stresor, medicinska sestra/tehničar

Datum primitka: 30.06.2015

Datum prihvaćanja: 02.03.2016.

Adresa za dopisivanje:

Samka Ekić, dipl. med. techn.

Klinika za psihijatriju

Klinička bolnica Dubrava

Avenija Gojka Šuška 6, 10000 Zagreb

E-pošta:samka.ekic@gmail.com 


\section{Uvod}

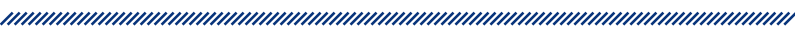

Stres je pojam koji označava stanje organizma u kojem doživljavamo prijetnju vlastitom integritetu. Pojam je upotrebljavan već u 14 . stoljeću u značenju patnje, muke, neprilike, tegobe, nesreće ili tuge ${ }^{1}$.

Kanadski liječnik Hans Selye 1936. godine počeo je upotrebljavati stres u vrlo specifičnom smislu, označavajući njime usklađeni skup tjelesnih obrana protiv štetnog podražaja bilo koje vrste².

Nakon dugotrajnog izlaganja stresnim situacijama dolazi do pojačanog lučenja kortikosteroida, povećanja kore nadbubrežne žlijezde te atrofije timusa i drugih limfatičkih struktura. Ovakve tjelesne odgovore opisao je R. Lazarus kao opći adaptivni sindrom ${ }^{3}$.

Richard Lazarus (1966.) razradio je teoriju stresa prema kojoj najveće značenje u stresnim zbivanjima imaju spoznajni (kognitivni) procesi, a središnji je pojam njegove teorije pojam ugroženosti. Ugroženost je, prema Lazarusu, stanje u kojem pojedinac predviđa sukob s ugrožavajućom situacijom ${ }^{4}$. Drugim riječima, Lazarus definira stres kao „stanje koje se javlja u situaciji nesklada između zahtjeva koje okolina postavlja pred pojedinca i njegovih mogućnosti reagiranja na te zahtjeve“"5.

Veliki broj zaposlenih u zdravstvenom sustavu čine medicinske sestre i tehničari. Zbog velike odgovornosti prema ljudskom životu i zdravlju, smjenski rad, 24-satna dežurstva, odgovornost pri donošenju ponekad brzih odluka, kontakt s obiteljima oboljelih i emocionalno iscrpljivanje povećava mogućnost nastanka psihosomatskih bolesti kao što su bolesti kardiovaskularnog sustava, npr. povišen krvni tlak, aritmije te ishemijske bolesti srca. Navedene bolesti spadaju u skupinu bolesti koje se povezuju s utjecajem stresa, a ujedno zauzimaju vodeće mjesto po smrtnosti u društvu ${ }^{4}$.

Djelovanje stresa povezuje se s bolestima sustava organa za kretanje kao što su: osjećaj ukočenosti zglobova bez patoloških promjena, psihogeni reumatizam, kronični umor i teško podnošenje tjelesnog napora - što dovodi do emotivne razdražljivosti ${ }^{4}$.

Sustav žlijezda s unutrašnjim izlučivanjem, uz autonomni živčani sustav, najodgovorniji je za promjene koje se u tijelu zbivaju pod utjecajem stresa, stoga se endokrinološke bolesti kao što su hipertireoza i dijabetes često stavljaju u navedenu skupinu ${ }^{4}$.
Stres utječe na dišni sustav na način da disanje postaje nepravilno, isprekidano i duboko. Bolest dišnog sustava za koju se najčešće spominje da je pod jakim utjecajem psihosomatskih mehanizama jest bronhalna astma ${ }^{4}$.

Nastanak nekih bolesti probavnog sustava kao što je akutni gastrointestinalni ulkus često se naziva i stres-ulkus, jer se pojavljuje kao reakcija na jak fiziološki stres ${ }^{4}$.

Stres može oslabiti imunološki sustav i time utjecati na pojavu bolesti.

Zdrav imunološki sustav regulira proces ozdravljivanja našeg tijela te ga štiti od infekcija i zaraznih bolesti. Stres može kompromitirati funkcioniranje imunološkog sustava, što može rezultirati prehladama, gripom, umorom, poremećajima krvožilnog sustava i $\mathrm{dr}^{6}{ }^{6}$

Kao posljedica dugotrajnih i jakih traumatskih stresova može nastati sindrom izgaranja na poslu (tzv. burn-out sindrom) i posttraumatski stresni poremećaj (PTSP) ${ }^{7}$.

Niska razina odlučivanja i visoki zahtjevi, karakteristični za sestrinsku profesiju, mogu biti povezani s povećanim rizikom za pojavu koronarne bolesti ${ }^{8}$ i mentalnih poremećaja9.

Među kineskim medicinskim sestrama najčešći su uzroci stresa: loša slika sestrinstva u društvu, organizacijski problemi te neravnoteža između uloženog i dobivenog ${ }^{10}$.

U zemljama u tranziciji povećan je broj medicinskih sestara koje napuštaju svoje radno mjesto ${ }^{11}$.

Studija na više od 2600 švedskih medicinskih sestara pokazala je da je $30 \%$ sestara izjavilo da je doživjelo nasilje na radnom mjestu, i to u psihijatrijskom sestrinstvu ${ }^{12}$ :

1. u $61 \%$ slučajeva došlo je do nasilnog ispada više od jedan put

2. $15 \%$ jednom

3. $24 \%$ nikad.

\section{Metode rada i uzorak}

Istraživanje je provedeno u Kliničkoj bolnici Dubrava u Zagrebu, odobrilo ga je Etičko povjerenstvo iste bolnice. Ispitanicima je objašnjena svrha istraživanja te da je sudjelovanje anonimno. Osigurana je tajnost i zaštita podataka koja poštuje etička načela. Sudjelovalo je 363 
medicinskih sestara i tehničara u dobnom rasponu od 19 do 62 godine, a samim time i raspon radnog staža kretao se od ispitanika s manje od jedne godine staža pa do ispitanika s 40 i više godina staža.

Ispitivanjem su obuhvaćene medicinske sestre i tehničari sa SSS-om, VŠS-om i VSS-om na svim radilištima. Najveći je broj medicinskih sestara srednje stručne spreme i radi na odjelu.

Sve medicinske sestre i tehničari imali su istu šansu biti uključeni u provedeno istraživanje.

Za istraživanje je korišten upitnik preuzet iz istraživanja kojega je provodila prof. dr. sc. Mirjana Grubišić-llić u istraživanju stresa u liječničkoj profesiji ${ }^{13}$. Upitnik je prilagođen istraživanju unutar profesije medicinskih sestara i tehničara, a sastoji se od sljedećih skupina pitanja:

1. sociodemografski podaci

2. vrste stresora za sve medicinske sestre i tehničare (24-satna odgovornost, neadekvatna primanja, svakodnevne nepredvidive situacije...)

3. vrste stresora na rukovodećem mjestu (odgovornost za stručno i administrativno funkcioniranje, nedostatak vremena za bavljenje bolesnicima...)

4. zdravstveni problemi (kardiovaskularne smetnje, probavne smetnje, lokomotorne smetnje...).

Statistička analiza učinjena je s pomoću programskih paketa Statistica v8 (StatSoft Inc., Tulsa, OK, SAD) i Microsoft Excel 2013 (Microsoft Inc., Redmond, SAD). U prikazu podataka primijenjene su metode deskriptivne statistike. Većina su varijabli generiranih u istraživanju kategorijske varijable te su prikazane frekvencije i udjeli pojedinih kategorija. Kontinuirane varijable, kao i varijable koje se odnose na intenzitet stresora, prikazane su aritmetičkom sredinom i standardnom devijacijom.

\section{Rezultati istraživanja}

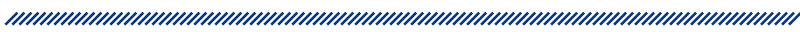

Ovim istraživanjem obuhvaćeno je 363 ispitanika. Kao što se vidi u tablici, raspon dobi ispitanika bio je širok (od 19 do 62 godine), a to se odražava i u rasponu radnog staža koji se kretao od ispitanika s manje od jedne godine radnog staža pa sve do ispitanika s više od 40 godina radnog staža. Uzorak su velikim dijelom sačinjavale žene $(89,1 \%)$, većina njih imala je završenu srednju medicinsku školu (78,8 \%), od kojih je 56,2 \% udano/ oženjeno i ima djecu. Njihovi bračni partneri u 89,7 \% slučajeva nisu zdravstveni djelatnici (tablica 1: Sociodemografski podaci $(\mathrm{N}=363)$ ).

Iz tablice 2 može se vidjeti da je više od polovice ispitanika radilo na odjelu. Smjenski rad bio je najzastupljeniji. Treba naglasiti da velikom dijelu ispitanika $(65,1 \%)$ postojeće radno mjesto nije bilo prvo. U 45,8 \% slučajeva

\begin{tabular}{|c|c|c|c|c|c|}
\hline $\mathrm{N}$ - broj ispitanika & & $\mathrm{X}$ & Raspon & $\mathrm{N}$ & $\%$ \\
\hline Dob (godine) & & 36,5 & $19-62$ & & \\
\hline Dužina radnog staža (godine) & & 16,6 & $0,1-41$ & & \\
\hline Spol & $\begin{array}{c}\text { Žene } \\
\text { Muškarci }\end{array}$ & & & $\begin{array}{c}319 \\
39\end{array}$ & $\begin{array}{l}89,1 \% \\
10,9 \%\end{array}$ \\
\hline Završeno školovanje & $\begin{array}{l}\text { SSS } \\
\text { VŠS } \\
\text { VSS }\end{array}$ & & & $\begin{array}{c}283 \\
62 \\
14 \\
\end{array}$ & $\begin{array}{c}78,8 \% \\
17,3 \% \\
3,9 \%\end{array}$ \\
\hline Bračno stanje & $\begin{array}{c}\text { Udana/oženjen } \\
\text { Neudana/neoženjen } \\
\text { Rastavljena/rastavljen } \\
\text { Izvanbračna zajednica } \\
\text { Udovica/udovac }\end{array}$ & & & $\begin{array}{c}200 \\
118 \\
18 \\
14 \\
6\end{array}$ & $\begin{array}{c}56,2 \% \\
33,1 \% \\
5,1 \% \\
3,9 \% \\
1,7 \%\end{array}$ \\
\hline Djeca & $\begin{array}{l}\mathrm{Da} \\
\mathrm{Ne}\end{array}$ & & & $\begin{array}{l}202 \\
136\end{array}$ & $\begin{array}{l}59,8 \% \\
40,2 \%\end{array}$ \\
\hline Zanimanje bračnog partnera & $\begin{array}{c}\text { Ostalo } \\
\text { Zdravstveni djelatnik }\end{array}$ & & & $\begin{array}{c}192 \\
22\end{array}$ & $\begin{array}{l}89,7 \% \\
10,3 \%\end{array}$ \\
\hline
\end{tabular}




\begin{tabular}{|c|c|c|c|}
\hline & & $\mathrm{N}$ & $\%$ \\
\hline Radno mjesto (1) & $\begin{array}{l}\text { Odjel } \\
\text { Intenzivna skrb } \\
\text { Ambulanta } \\
\text { Odjel i ambulanta }\end{array}$ & $\begin{array}{l}175 \\
86 \\
55 \\
29\end{array}$ & $\begin{array}{c}50,7 \% \\
24,9 \% \\
15,9 \% \\
8,4 \%\end{array}$ \\
\hline Radno mjesto (2) & $\begin{array}{c}\text { Smjenski rad } \\
\text { Rukovodeće mjesto }\end{array}$ & $\begin{array}{l}250 \\
26\end{array}$ & $\begin{array}{l}72,9 \% \\
7,6 \%\end{array}$ \\
\hline Promjena radnog mjesta & $\begin{array}{l}\mathrm{Da} \\
\mathrm{Ne}\end{array}$ & $\begin{array}{l}233 \\
125\end{array}$ & $\begin{array}{l}65,1 \% \\
34,9 \%\end{array}$ \\
\hline Razlog promjene radnog mjesta & $\begin{array}{l}\text { Ostalo } \\
\text { Višekratni ugovori na određeno radno vrijeme } \\
\text { Nezadovoljstvo odnosima na radnom mjestu i organizacijom posla } \\
\text { Obiteljski razlozi } \\
\text { Nemogućnost napredovanja }\end{array}$ & $\begin{array}{l}108 \\
68 \\
31 \\
19 \\
10\end{array}$ & $\begin{array}{l}45,8 \% \\
28,8 \% \\
13,1 \% \\
8,1 \% \\
4,2 \%\end{array}$ \\
\hline
\end{tabular}

razlog promjene radnog mjesta bili su višestruki ugovori na određeno vrijeme. To je ujedno bio najčešći razlog promjene radnog mjesta koji smo uspjeli identificirati. Znatan dio ispitanika ulazio je u kategoriju Ostalo, što znači da postoje drugi razlozi promjene radnog mjesta koje ovim istraživanjem nismo obuhvatili (tablica 2: Karakteristike radnog mjesta).

Tablica 3 prikazuje 25 stresora koje možemo očekivati na poslu medicinskih sestara i tehničara - preuzetih iz upitnika Stres u liječničkoj profesiji. Tablica prikazuje ljestvicu poretka stresora napravljenu na temelju aritmetičke sredine subjektivne ocjene ( 1 - 5). Pri tome je stresor „neadekvatne plaće“ ocijenjen kao najstresniji $(3,91)$, a „komunikacija s osobama oštećena sluha ili vida" kao najmanje stresna situacija $(2,49)$. Općenito se može reći da dominiraju stresori koji su povezani s opsegom i nepredvidivošću posla te osjećaj neadekvatne naknade. Zanimljivo je da su stresori koji se odnose na međusobnu komunikaciju unutar tima (redni brojevi 21. i 24.) relativno nisko ocijenjeni $(2,77-2,58)$ (tablica 3: Klasifikacija prema stresorima).

U provedenom istraživanju (tablica 4) izdvojeni su stresori za medicinske sestre i tehničare na rukovodećim mjestima. Pri tom su prekapacitiranost poslom općenito i nedostatak vremena za bavljenje bolesnicima ocijenjeni kao najstresniji, $(3,63)$, a stresor „osjećaj izoliranosti od kolegica i kolega vezano uz funkciju rukovodeće osobe" kao najmanje stresan $(2,77)$ Odgovornost za stručno i administrativno funkcioniranje odjela u vezi s poslovima medicinske sestre i tehničara također je visoko ocijenjena $(3,39)$ (tablica 4: Stresori na rukovodećim položajima).
Iz tablice 5 vidljivo je da je znatan dio ispitanika izvijestio o postojanju dugotrajnih zdravstvenih problema kroničnog karaktera. Zabilježena je vrlo slična učestalost kardiovaskularnih bolesti (32,50\%), probavnih smetnji $(32,10 \%)$ i lokomotornih smetnji, koje su ujedno bile najzastupljenije $(29,20 \%)$ (tablica 5: Zdravstvene tegobe kao posljedice stresa).

\section{Rasprava}

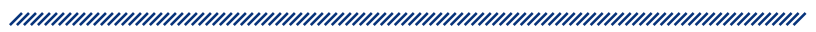

Svrha ovog istraživanja bila je istražiti utjecaj stresa na svakodnevni posao u populaciji medicinskih sestara i tehničara.

Rezultati istraživanja pokazuju da su, bez obzira na to na kojem radnom mjestu medicinske sestre rade, stresori prisutni u različitom intenzitetu, a odnose se na preopterećenost poslom, lošu organizaciju i zahtjevne administrativne poslove.

Rezultati istraživanja upozoravaju na potrebu smanjenja stresora na radnom mjestu - što se može postići kvalitetnijom organizacijom rada unutar svake ustrojstvene jedinice, kontinuiranom edukacijom i popunjavanjem kadra, barem približno prema standardima kakvi su postavljeni u razvijenijim zemljama. 


\section{Tablica 3. Klasifikacija prema stresorima}

\begin{tabular}{|c|c|c|c|}
\hline & Stresori & $\mathrm{X}$ & SD \\
\hline 1 & Neadekvatne plaće & 3,91 & 1,20 \\
\hline 2 & Dežurstvo (hitna služba) & 3,79 & 1,19 \\
\hline 3 & 24-satna odgovornost & 3,79 & 1,19 \\
\hline 4 & Prekapacitiranost poslom & 3,63 & 1,16 \\
\hline 5 & $\begin{array}{l}\text { Hitne odluke koje donosite sami bez } \\
\text { mogućnosti konzultacije }\end{array}$ & 3,56 & 1,28 \\
\hline 6 & Svakodnevne nepredvidive situacije & 3,50 & 1,22 \\
\hline 7 & $\begin{array}{l}\text { Verbalna agresija, prijetnje od strane } \\
\text { bolesnika ili članova obitelji }\end{array}$ & 3,48 & 1,35 \\
\hline 8 & $\begin{array}{l}\text { Komunikacija s teškim ili neizlječivim } \\
\text { bolesnicima }\end{array}$ & 3,43 & 1,27 \\
\hline 9 & $\begin{array}{l}\text { Komunikacija s obitelji teškog ili } \\
\text { neizlječivog bolesnika }\end{array}$ & 3,38 & 1,23 \\
\hline 10 & Smjenski rad & 3,35 & 1,25 \\
\hline 11 & $\begin{array}{l}\text { Prekidanje posla uslijed telefonskih } \\
\text { poziva }\end{array}$ & 3,32 & 1,29 \\
\hline 12 & Komunikacija s bolesnom djecom & 3,29 & 1,36 \\
\hline 13 & $\begin{array}{l}\text { Komunikacija s osobama koje imaju } \\
\text { psihičke poremećaje }\end{array}$ & 3,27 & 1,25 \\
\hline 14 & $\begin{array}{l}\text { Prevelika, nerealna očekivanja od } \\
\text { bolesnika i članova obitelji }\end{array}$ & 3,24 & 1,20 \\
\hline 15 & $\begin{array}{l}\text { Verbalna agresija, prijetnje od strane } \\
\text { kolega ili drugih članova tima }\end{array}$ & 3,20 & 1,36 \\
\hline 16 & $\begin{array}{l}\text { Pritisci, neprimjereni komentari, zahtjevi } \\
\text { i očekivanja od strane nadređenih osoba }\end{array}$ & 3,13 & 1,25 \\
\hline 17 & $\begin{array}{l}\text { Administrativni poslovi i birokracija } \\
\text { općenito }\end{array}$ & 3,09 & 1,32 \\
\hline 18 & Nerealne bolesničke pritužbe & 3,04 & 1,27 \\
\hline 19 & Nedostatak vremena za edukaciju & 3,03 & 1,19 \\
\hline 20 & $\begin{array}{l}\text { Nedostatan broj iskusnijih medicinskih } \\
\text { sestara na odjelu / službi }\end{array}$ & 2,95 & 1,19 \\
\hline 21 & Odnosi s drugim članovima tima & 2,77 & 1,15 \\
\hline 22 & $\begin{array}{l}\text { Poremećaji obiteljskog života uzrokovani } \\
\text { radnim obvezama }\end{array}$ & 2,75 & 1,21 \\
\hline 23 & Neadekvatno radno okružje & 2,71 & 0,85 \\
\hline 24 & $\begin{array}{l}\text { Odnosi s kolegicama/kolegama } \\
\text { (komunikacijska razina) }\end{array}$ & 2,58 & 1,16 \\
\hline 25 & $\begin{array}{l}\text { Komunikacija s osobama oštećena sluha } \\
\text { ili vida }\end{array}$ & 2,49 & 1,18 \\
\hline \multicolumn{4}{|c|}{$\begin{array}{l}\mathrm{X} \text { - aritmetička sredina } \\
\text { SD - standardna devijacija }\end{array}$} \\
\hline
\end{tabular}

\section{Tablica 4. Stresori na rukovodećim položajima}

\begin{tabular}{|l|l|l}
\hline Stresori & $X$ & SD
\end{tabular}

1 Prekapacitiranost poslom općenito $\quad 3,63 \quad 1,12$

Nedostatak vremena za bavljenje

bolesnicima

$3,43 \quad 1,17$

Odgovornost za stručno i

3 administrativno funkcioniranje odjela

vezano uz poslove medicinske sestre $i$ tehničara

\begin{tabular}{|l|l|l|l|}
4 & Previše administrativnih poslova & 3,34 & 1,31 \\
\hline
\end{tabular}

5 Nemogućnost utjecaja na razna

5 administrativna ograničenja

Pritisci, neprimjereni komentari,

6 zahtjevi i očekivanja od strane suradnika $3,23 \quad 1,33$ (podređenih u hijerarhiji)

7 Previše vremena provedenog na loše

7 organiziranim i nepotrebnim sastancima

8 Osjećaj izoliranosti od kolegica/kolega

8 vezano uz funkciju rukovodeće osobe

\section{Zaključak}

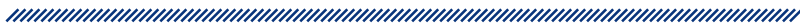

Odabirom rezultata specifičnih za rad medicinskih sestara i tehničara može se zaključiti da je, od 25 navedenih stresora koji se mogu detektirati u profesiji, stresor neadekvatne plaće ocijenjen kao najstresniji, a komunikacija s osobama oštećena vida ili sluha kao najmanje stresna. Stresori koji se odnose na komunikaciju unutar tima nisko su ocijenjeni. 
Prekapacitiranost poslom te odgovornost za stručno i administrativno funkcioniranje odjela medicinske sestre i tehničari na rukovodećem mjestu ocijenili su najviše stresnim. Visoko je ocijenjen i stresor „nedostatak vremena za bavljenje bolesnicima“, a stresor „osjećaj izoliranosti od kolegica i kolega vezano uz funkciju rukovodeće osobe" prikazan je kao najmanje stresan.

Najučestalije zdravstvene tegobe kao posljedica stresa rangirane su na sljedeći način: kardiovaskularne smetnje, probavnesmetnjetesmetnje lokomotornogsustava.

Medicinske sestre i tehničari edukacijom, znanjima i vještinama u profesionalnom radu lakše se mogu prilagoditi stresnim događajima. Korištenjem vještinama kao što su: komunikacija s bolesnicima i njihovim obiteljima, komunikacija s kolegama, komunikacija s nadređenima, profesionalna edukacija, organiziranje slobodnog vremena, tjelesna aktivnost, relaksacija, meditacija, joga i autogeni trening pridonijet će smanjenju razine stresa, olakšati obavljanje posla i donošenje odluka te postizanje osobnih ciljeva i većeg zadovoljstva u radu.

\section{Literatura}

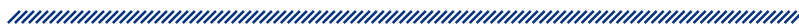

1. Lumsden DP. Is the concept of "stress" of any use, anymore? U: Randall, D, ur. Contributions to primary intervention in mental health: Working papers. Toronto; 1981.

2. Selye H. A Syndrome Produced by Diverse Nocuous Agents. Nature. 1936;138:32.

3. Lazarus RS, Folkman S. Stress, Appraisal and Coping. New York: Springer Publishing Company; 1984.

4. Havelka M. Zdravstvena psihologija. Zagreb: Medicinski fakultet Sveučilišta u Zagrebu; 1998.

5. Havelka M. Zdravstvena psihologija. Zagreb: Medicinski fakultet Sveučilišta u Zagrebu; 1990.

6. McLeod SA. Stress, Illness and the Immune System [Internet]. Dostupno na: http://www.simplypsychology. org/stress-immune.html (pristupljeno 6. siječnja 2016.)

7. Havelka M, Havelka Meštrović A. Zdravstvena psihologija. Zagreb: Zdravstveno veleučilište; 2013.

8. Bosma H, Marmot MG, Hemingway $\mathrm{H}$, Nicholson AC, Brunner E, Stansfeld SA. Low job control and risk of coronary heart disease in Whitehall II (prospective cohort) study. BMJ. 1997;314(7080):558-65.

9. Stansfeld SA, Candy B. Psychosocial work environment and mental health - metaanalytic review. Scandinavian Journal of Work, Environment, and Health. 2006;32:443-462.

10. Zeng Y. Review of work-related stress in mainland Chinese nurses. Nursing and Health Sciences. 2009;11:90-97.

11. Hasselhorn HM, Tackenberg P, Peter R. Next-Study Group. Effort-reward imbalance among nurses in stable countries and in countries in transition. International Journal of Occupational and Environmental Health. 2004;10:401-408.

12. Arnetz JE, Arnetz BB, Petterson IL. Violence in the nursing profession: occupational and lifestyle risk factors in Swedish nurses. Work \& Stress. 1996;10:119-127.

13. Grubišić--llić M. Stres i zdravlje bolničkih liječnika. U: Zbornik radova. 4. hrvatski simpozij o poremećajima uzrokovanim stresom s međunarodnim sudjelovanjem: Stres i zdravlje; 2009; Rabac, Hrvatska. 


\section{PROFESSIONAL STRESS IN NURSES}

1 Samka Ekić

1 Ana Primorac

1 Boris Vučić

1 University Hospital Dubrava, Zagreb, Croatia

\section{Abstract}

The aim of this research was to determine the influence of stress on the perfomance of nurses' everyday activities.

Data was collected anonymously using a questionnaire specifically designed for this purpose. The questionnaire included sociodemographical data of the respondents, stressors common to all nursing professionals, specific stressors that occur in management positions and health issues of the respondents. In the statistical analysis, continuous variables were presented using an arithemic mean and standard deviation. The research included 363 participants that work in different working environments: hospital ward, polyclinics and diagnostics departments. Most of the respondents work in the hospital ward in shifts, that is 175 of them $(50.7 \%)$. Out of the total number of respondents in the hospital ward 86 of them (24.9\%) work in the intensive care department.

With regard to the aim of the research, it was necessary to determine how some of the stressors in nursing are ranked by intensity. Based on the given results, it can be concluded that the dominant stressors are the ones related to a feeling of inadequate compensation and unpredictable workload - such as a 24-hour work responsibility and the need to make urgent decisions without the possibility of consult. Work overload and the lack of time for patient care present in nursing management positions were ranked as the highest-intensity stressor, while isolation from coworkers in the workplace was ranked as the lowest-intensity one. Stressors connected to interpersonal communication within the team were ranked low.

As previously mentioned, the questionnaire included a section dedicated to health issues that emerged as a consequence of stress. Out of the total number of respondents, 212 of them $(60,90 \%)$ point out to chronic health issues, wherein the health issues last more than a year. Given results also suggest frequent cardiovascular diseases (elevated blood pressure, circulatory disorders), indigestion and locomotor disorders. 